\title{
Adaptability Efficiency in the Context of Management and Economics: Origin and Development
}

\author{
Manli Cheng ${ }^{\mathrm{a}}$ and Bo Chen \\ Institute of Defense Economics and Management, Central University of Finance and Economics, \\ Beijing, 100081, China. \\ amanli130@126.com
}

Keywords: Classical organization theory, bureaucracy, neoinstitutional economics, revolutionary economics.

\begin{abstract}
The thesis analyzes the origin and development of the concept "adaptability efficiency" in the research field of management and economics. It finds out that, the research has changed from a static to dynamic way, a unique to complex view. The most favored method to study organization should combine the dynamic, historical way and tactic, internal way together. Taylor's scientific management improves production rationalization through standardizing process to ensure workshop's efficiency, and the purely bureaucratic type of administrative organization has become very popular as its capability of attaining the highest degree of efficiency(from a purely technical point of view). Efficiency is mentioned static resource distribution efficiency traditionally, but it cannot reflect the dynamic change in economy and institution. North strengthens that the institutional "adaptability efficiency" rather than production factors "distribution efficiency" decides the long-term economic growth. "Adaptability efficiency" means the ability of sustainable development of institution adjusting to the environment. So what is the logic behind "adaptability efficiency" in the research of management and economics; how they discuss "organization" in different theories; and what can we learn from it
\end{abstract}

\section{Organizational Adaptability: in the View of Organizational Management Theory}

\subsection{Classical Organization Theory: Seldom Considering Organization Adaptability Problems.}

The classical organization theory hasn't focused on the adaptability capability of the organization; otherwise, it treats organization as a mechanical and closed system. In classical organization view, a company improves its status in market competition through increasing working efficiency. For example, Taylor's scientific management carries out standardization and production rationalization, focusing on cooperation and specialization. Max Weber thinks that bureaucracy is more efficient than other forms of organizations. Bureaucracy is the output of capitalism, as capitalist economy demands doing things with high coordination and strict precision [1]. In Collins' view, bureaucracy distinguishes the rational system from the previous research in the context of developing rationality in the western world [2].

In a sum, the classical organization theory focuses on preciseness and efficiency, and thinks the organization rationality is an efficient tool to overcome mankind's bounded rationality. It takes too much attention on the pure technology advantage for an organization rather realizing the organization's adaptability to the environment.

\subsection{Modern Management Theory: Organization vs. Environment.}

Modern management theory begins to research the influence of environment that traditional theories ignore. According to the open systematic view, the organization can only survive if it adapts to the change of environment. It emphasizes reinforcing the management control so as to help the organization adapt to the environment, however, it ignores the deciding role of the organization form as well as the mechanism between the organization and environment. The recent research about organization adapts to environment demands establishing "aheterarchy" of decision-making. It advocates setting up different levels of decision-making and cooperation among every kinds of 
elements. It's thought that the decentralized decision-making body could solve problems in a more innovative way. The contingency theory pays much more attention to the outside environment and flexibility of decision-making [3].

\subsection{Organization Dysfunction and Adaptability.}

Since the 1950s, some organization theorists have realized the boundary of organization theory which focused on the rationality and efficiency, and raised the thought of organization dysfunction. Some researchers find out the paradox between organization efficiency and long-time adaptability. For example, March (1999) points out that organization's stability is at the expense of reducing the capability of adapting to new organizations [4]. Therefore, the focus of organization theory has changed from efficiency-oriented to relation between efficiency and adaptability.

Merton (1958) first raises the organization dysfunction. Generally speaking, bureaucracy increases efficiency on the one hand, but behaviors of self protectionism is inefficient in nature [5]. Above on the observation of public organizations, Crozier (1964) believes that rules could manage all kinds of contingency in the so called stable world as bureaucracy pursues for, but seldom leave much room for personal decision-making, and this has becomes the main reason behind the organization low adaptability. Crozier then raises the theory of "doubtful circle of bureaucracy dysfunction [6]. Alson (1971) believes that a rational and self-interest oriented person would not take action to realize the common interest of the organization; therefore, the organization's adaptability to the environment is reduced [7].

The more adaptability the organization has, the more efficiency it will own; however its realizing cost has increased as well. Shouyong (2004) analyzes bureaucracy and corruption in a decentralized exchange market [8], finds out the inherent necessity between bureaucracy and corruption. In the post-industrial society, the controlling function of bureaucracy has become impossible because of complexities and uncertainties of the real world [9]. As the development of the third technological revolution, bureaucracy has not been suitable for the present society, and its disadvantages has become increasingly obvious [10].

\section{Organizational Adaptability: in the View of Economics}

In the field of classical economics, the research topic is the problem of resource allocation. Since Ronald $\mathrm{H}$. Cease brings the enterprise organization theory into the field of economics through transaction cost. In eyes of most new institutional economists, the organization is a series of contracts, which is deviated from the nature characteristic of social activities as an organization should act as. However, based on the research on European economic history, North (1993) says, an efficient economic organization is the important reason of western world development [11]. He finds out the deciding role of adaptability efficiency in the way of economic change. To some extent, the economics research has paid more attention on the role of adaptability efficiency in the long-time economic performance.

\subsection{Traditional Economics: Seldom Considering Organization Problems.}

In Adam Smith view, the task of economics research is to identify the nature and cause of nations' wealth. The famous "Smith Theorem" tells us division of labor is the source of economic growth, it decides the size of market which is formed by transportation [12]. Also Smith doesn't treat business organization as the research object; the thought of "division of labor" is the key of understanding the organization. Soon afterwards, Alfred Marshall treats "organization” as the fourth production factor into his economics theory, organization acts as a function of labor division coordination. He doesn't distinguish the price mechanism and organization coordinating role in economic activities. Therefore, the classical economics couldn't answer the question of nature of the organization; neither could focus on the relation between organization and environment.

\subsection{Neoinstitutional Economics: Adaptability Efficiency in the Preliminary Stage.}

Based on the relation between the firm and market, Ronald H. Cease (1937) explains the reason for the existence of firm, where the boundary is decided by contracts through the transaction cost analysis [13]. However, contract is incomplete, adverse selection and moral hazard is inevitable [14]. 
Succeeding economists study the organization in the context of transaction cost, however, they do not realize the nature of the firm is not just a series of contracts, but the human social relation formed in a firm's activities.

North puts forward a concept named "adaptability efficiency" based on his long research on institutional change and economic performance [15]. In his view, the mutual relation between organization and institution is not just simple resource allocation efficiency. As for allocation efficiency, the classic Pareto Optimality exists in the context of a firm's production. But on the other side, the long-time method of the evolution forming economic growth is what "adaptability efficiency" truly cares for. In Williamson's view, adaptability is the central problem of economic organization [16], he tries to establish some kind of connection between transaction and governance structure [17].

\subsection{Evolutionary Economics: Adaptability Efficiency.}

The institution's adaptability to economic change has been brought into the field of evolutionary economics research. Things could not change in the way you predict, we have to adjust ourselves to those changes.

Evolution is the process of endogenous change in an open system, an idea that owes just as much to Smith and Hayek and liberal economics as it does to Darwin and biology. Evolution is a theory of endogenous change, and Darwin's central idea was that three primary mechanisms (selection, variation and replication) were sufficient to generate a process of ongoing adaptive change. This idea is at the heart of both evolutionary biology and evolutionary economics [18]. Economic change is a dynamic evolutionary process, although most economic foundations are based on equilibrium, stabilization and conclusiveness (Marshall, 2013) [19].

Drawing lessons from biological evolution and other natural science research, evolutionary economics analyses the operation and development of economic system in a more dynamic and evolutionary way through institutional change and technology innovation. Innovation should be thought in the core place of theoretical system of analyzing how world goes on. In the context of evolutionary economics, the combination of innovation and convention lies not only in technology, but also in organization and management. Innovation means changing the original way and fighting against the path dependence, uncertainties and time- irreversibility [20]. Self-organization theory and evolutionary game theory are main methods to analyze the dynamic process, while system dynamics and complex system theory are main methods to model the real world.

\section{Reviews on Adaptability Efficiency in Management and Economics Theories}

(1) Traditional organization and economics treat the behavior of the firm as a "black box" , but analyses it by production function in the principle and benefit maximization and cost minimization.

(2) Neoinstitutional economics discusses the nature of organization in the context of contracts and institutions, and raise out a concept named "institution adaptability". It finds a new way to research the relation between organization and performance, but it does not explain the concept systematically, neither set up a formulation of institution adaptability. And most importantly, neoinstitutioanl economists ignore what role the political interest group play in the institutional change. Interest groups act differently in different situations decided by their bargaining power and compromises. Therefore, interest groups with strong power will maintain the poor performance to protect their vested interests through their own disposable resources.

(3) Evolutionary economics studies the mutual relation among social, political, economic, historical and cultural factors influencing the way of economic institutional change on the beginning of considering "organization adaptability”. However, it would bring another question when studies organization only in a dynamic and evolutionary way. It ignores the internal organization structure and organization social relationship aspects about the organization adaptability. In a sum, organization research in a view of adaptability should combine the dynamic, historical way as well as tactic, internal way together. 


\section{References}

[1]. Jenks, Leland H. Social and Economic Thought from Max Weber: Essays in Sociology. Translated, edited, and with an Introduction by H. H. Girth and C. Wright Mills. New York: Oxford University Press, 1946. pp. 490. Max Weber: The Theory of Social and Economic Organ. Journal of Economic History 8.1(1948):p555-9.

[2]. Collins, Randall. Conflict Sociology: Toward an Explanatory Science. Journal for the Scientific Study of Religion 15.2(1975).

[3]. Chakravarthy, Bale, and J. Henderson. From a hierarchy to a hierarchy of strategies: adapting to a changing context. Management Decision45.3 (2007):p642-652.

[4]. Miner, Anne S. The Pursuit of Organizational Intelligence, by James G. March. The pursuit of organizational intelligence. Blackwell Business, 1999:p174-178.

[5]. Davy, G. Social theory and social structure: towards the codification of theory and research- 1 vol. by Robert K. Merton. Bum Cardiovascular Disorders 13.Suppl 1(2013):p189-207.

[6]. Crozier, Michel. The bureaucratic phenomenon. American Journal of Sociology 10.2(1964).

[7]. Olson, Mansur. The logic of collective action: public goods and the theory of groups. Harvard University Press, 1971.

[8]. Shi, Shooing, and T. T. A model of bureaucracy and corruption." International Economic Review 45.3(2004):p873-908.

[9]. Liu X Q, Zhuang G B. Bureaucracy and public power supervision. Journal of Guangdong University of Administration (2011)23.5:pp25-29.

[10]. PU F. Research on organization dilemma and behavior paradox of power supervision in the view of bureaucracy. Administrative Science Forum (2017)12:p43-49.

[11]. North, Douglass Cecil. Structure and Change in Economic History. Structure and change in economic history. Norton, 1981.

[12]. Smith, Adam. An Inquiry into the Nature and Causes of the Wealth of Nations. An inquiry into the nature and causes of the wealth of nations. China Social Sciences Pub. House, 1999:7-8.

[13]. R. H. Cease. The Nature of the Firm. Economical (2010)4.16:386-405.

[14]. Karloff, George A. The Market for Lemons. Journal of Economics7.16 (1970):1372.

[15]. Scout, Adrian, and D. C. North. "Institutional Change and Economic Performance." Economic Journal 101.409(1990):1587.

[16]. Oliver E. Williamson. Transaction-Cost Economics: The Governance of Contractual Relations. The Journal of Law and Economics, 1979, 22(2):p233-261.

[17]. Doper, K. The evolutionary foundations of economics. Kurt Doper (2005).

[18]. Potts, Jason. Evolutionary economics: Foundation of liberal economic philosophy. Policy 19.1 (2003): p58-62.

[19]. Marshall, Alfred. Principles of economics. Political Science Quarterly31.77 (2013): p 430 $-444$.

[20]. Magnusson, and Lars. Evolutionary economics and path dependence. Edward Elgar, 1997. 